\title{
Retraction Note to: A Determinantal Expression for the Fibonacci Polynomials in Terms of a Tridiagonal Determinant
}

\author{
Feng $Q^{1,2,4}{ }^{1} \cdot$ Jing-Lin Wang ${ }^{3,4}\left([) \cdot B a i-N i\right.$ Guo ${ }^{2}(\mathbb{C}$
}

Published online: 13 October 2020

() Iranian Mathematical Society 2020

\section{Retraction to: Bulletin of the Iranian Mathematical Society (2019) 45:1821-1829 https://doi.org/10.1007/s41980-019-00232-4}

The Editor-in-Chief has retracted the original article [1] because it significantly overlaps with a number of previously published articles [2-4]. This article is therefore redundant.

All authors do not agree to this retraction.

\section{References}

1. Qi, F., Wang, J. \& Guo, B.: A determinantal expression for the Fibonacci polynomials in terms of a tridiagonal determinant. Bull. Iran. Math. Soc. 45, 1821-1829 (2019). https://doi.org/10.1007/s4198 0-019-00232-4

The original article can be found online at https://doi.org/10.1007/s41980-019-00232-4.

\section{Bai-Ni Guo}

bai.ni.guo@gmail.com; bai.ni.guo@hotmail.com

Feng Qi

qifeng618@gmail.com; qifeng618@hotmail.com

https://qifeng618.wordpress.com

Jing-Lin Wang

jing-lin.wang@hotmail.com

1 College of Mathematics, Inner Mongolia University for Nationalities, Tongliao 028043, Inner Mongolia, China

2 School of Mathematics and Informatics, Henan Polytechnic University, Jiaozuo 454010, Henan, China

3 Teda No. 2 Primary School, No. 98, The Fifth Street, Economic and Technological Development Zone, Tianjin 300457, China

4 School of Mathematical Sciences, Tianjin Polytechnic University, Tianjin 300387, China 
2. Qi, F., Guo, B.-N.: Expressing the generalized Fibonacci polynomials in terms of a tridiagonal determinant. Le Matematiche LXXII(Fasc. I), 167-175 (2017). https://doi.org/10.4418/2017.72.1.13

3. Qi, F., Cernanova, V., Semenov, Y.S.: Some tridiagonal determinants related to central Delannoy numbers, the Chebyshev polynomials, and the Fibonacci polynomials. Politehn. Univ. Buchar. Sci. Bull. Ser. A 81(1) (2019)

4. Qi, F., Liu, A.-Q.: Alternative proofs of some formulas for two tridiagonal determinants. Acta Univ. Sapientiae Math. 10(2), 287-297 (2018). https://doi.org/10.2478/ausm-2018-0022

Publisher's Note Springer Nature remains neutral with regard to jurisdictional claims in published maps and institutional affiliations 